\title{
Erratum to: Therapeutic clowns in pediatrics: a systematic review and meta-analysis of randomized controlled trials
}

\author{
Kannan Sridharan $^{1} \cdot$ Gowri Sivaramakrishnan ${ }^{2}$
}

Published online: 10 March 2017

(C) Springer-Verlag Berlin Heidelberg 2017

Erratum to: Eur J Pediatr (2016) 175:1353-1360

DOI 10.1007/s00431-016-2764-0

The original version of this article unfortunately contained errors. The errors are enumerated below:

\begin{tabular}{lcc}
\hline Place & Original text & To be replaced with \\
\hline $\begin{array}{l}\text { Abstract (Page 1/10) } \\
\text { A total of } 19 \text { studies were found eligible to be included } \\
\text { in the systematic review and } 16 \text { for meta-analysis. }\end{array}$ & $\begin{array}{c}\text { A total of } 18 \text { studies were found eligible to be included } \\
\text { in the systematic review and } 15 \text { for meta-analysis. }\end{array}$ \\
$\begin{array}{l}\text { Results - First paragraph } \\
\text { (Page 5/10) }\end{array}$ & $\begin{array}{c}\text { A total of } 91 \text { studies were obtained from the electronic } \\
\text { databases of which finally } 19[1,3,7,9,13,15-7, \\
19-2,25,29,30,41-43,48] \text { were found eligible to } \\
\text { be included. }\end{array}$ & $\begin{array}{c}\text { A total of } 91 \text { studies were obtained from the electronic } \\
\text { databases of which finally } 18[1,6,8,12,14-6, \\
18-1,24,28,29,40-42,47] \text { were found eligible to } \\
\text { be included. }\end{array}$ \\
$\begin{array}{l}\text { Results - First paragraph } \\
\text { (Page 6/10) }\end{array}$ & $\begin{array}{c}\text { Of the } 19 \text { studies, three }[9,21,25] \text { did not report the } \\
\text { outcome measures appropriately to be included in } \\
\text { the quantitative synthesis }\end{array}$ & $\begin{array}{l}\text { outcome measures appropriately to be included in } \\
\text { the quantitative synthesis }\end{array}$ \\
$\begin{array}{l}\text { Results - First paragraph } \\
\text { (Page 6/10) }\end{array}$ & $\begin{array}{c}\text { Hence, a total of } 16 \text { studies were included for the final } \\
\text { meta-analysis. }\end{array}$ & $\begin{array}{c}\text { Hence, a total of } 15 \text { studies were included for the final } \\
\text { meta-analysis. }\end{array}$
\end{tabular}

The online version of the original article can be found at http://dx.doi.org/ 10.1007/s00431-016-2764-0.

\footnotetext{
Kannan Sridharan

skannandr@gmail.com

Gowri Sivaramakrishnan

gowri.sivaramakrishnan@gmail.com

1 Department of Health Sciences, College of Medicine, Nursing and Health Sciences, Fiji National University, Suva, Fiji

2 Department of Oral Health, College of Medicine, Nursing and Health Sciences, Fiji National University, Suva, Fiji
} 
(Continuation of Corrections)

Place

Results - Second last paragraph (page 7/10)

Results - Last paragraph (Page 7/10)

Results - Figure 8 (Page 8/10)

References
Original text

Number of children requiring the use of anxiolytics Two studies in a total of 522 children reported the total number of children requiring the use of anxiolytics. The pooled relative risk was found to be 0.47

$[0.15,1.53]$ and was not statistically significant (Fig. 8)

Only one of the studies reported the time taken for induction of anesthesia, number of parents satisfied with the given care, number of interruptions by the healthcare staff and number of parents with anxiety, thus could not be used for the meta-analysis.

Figure 8
To be replaced with

This paragraph has to be removed.

Only one of the studies reported the time taken for induction of anesthesia, number of parents satisfied with the given care, number of interruptions by the healthcare staff, number of children using anxiolytic drugs and number of parents with anxiety, thus could not be used for the meta-analysis.

Figure 8 to be removed

Reference number 3 to be removed. References 1 and 2 remain the same. The references to be re-ordered as follows:

4-3; 5-4; 6-5; 7-6; 8-7; 9-8; 10-9; 11-10; 12-11;

$13-12 ; 14-13 ; 15-14 ; 16-15 ; 17-16 ; 18-17 ; 19-18$;

$20-19 ; 21-20 ; 22-21 ; 23-22 ; 24-23 ; 25-24 ; 26-25$;

$27-26 ; 28-27 ; 29-28 ; 30-29 ; 31-30 ; 32-31 ; 33-32$;

$34-33$; 35-34; 36-35; 37-36; 38-37; 39-38; 40-39;

$41-40 ; 42-41 ; 43-42 ; 44-43 ; 45-44 ; 46-45 ; 47-46$;

$48-47$. 